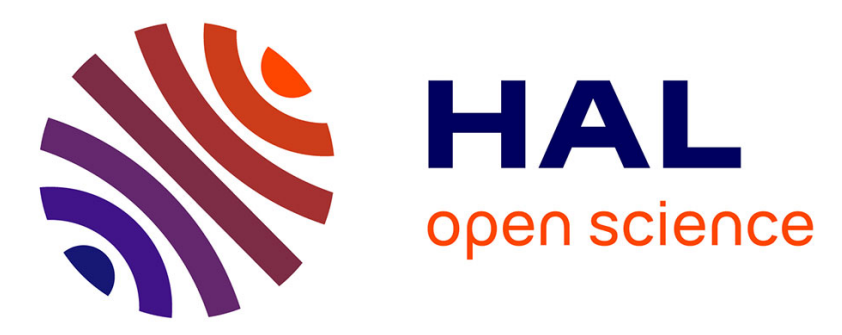

\title{
Massive structure monitoring: relevance of surface strain measurement
}

\author{
Maxime Boucher, Matthieu Briffaut, Frédéric Dufour
}

\section{To cite this version:}

Maxime Boucher, Matthieu Briffaut, Frédéric Dufour. Massive structure monitoring: relevance of surface strain measurement. CFM 2015 - 22ème Congrès Français de Mécanique, Aug 2015, Lyon, France. hal-03446497

\author{
HAL Id: hal-03446497 \\ https://hal.science/hal-03446497
}

Submitted on 24 Nov 2021

HAL is a multi-disciplinary open access archive for the deposit and dissemination of scientific research documents, whether they are published or not. The documents may come from teaching and research institutions in France or abroad, or from public or private research centers.
L'archive ouverte pluridisciplinaire HAL, est destinée au dépôt et à la diffusion de documents scientifiques de niveau recherche, publiés ou non, émanant des établissements d'enseignement et de recherche français ou étrangers, des laboratoires publics ou privés. 


\title{
Massive structure monitoring: relevance of surface strain measurement
}

\author{
M. BOUCHER ${ }^{\mathrm{a}, \mathrm{b}}$, M. BRIFFAUT ${ }^{\mathrm{a}, \mathrm{b}}$, F. DUFOUR ${ }^{\mathrm{a}, \mathrm{b}, \mathrm{c}}$ \\ a. Univ. Grenoble Alpes, 3SR, F-38000 Grenoble, France. \\ b. CNRS, 3SR, F-38000 Grenoble, France. \\ c. Chair professor PERENITI \\ e-mail : maxime.boucher@,3sr-grenoble.fr, matthieu.briffaut@3sr-grenoble.fr , \\ frederic.dufour@3sr-grenoble.fr
}

\begin{abstract}
Keywords: Thermo-Hydro-Mechanical Behaviour, Concrete, Massive Structure, Variable Environnemental Conditions, Surface Monitoring.
\end{abstract}

\begin{abstract}
:
For nearly 80 years, most of large concrete structures are instrumented with vibratory strain gauge. On some structures such as confinement vessels of nuclear power plants (highly prestressed), operators have to cope with the eventual loss of signal from some sensors. This may happen due to several reasons including a default in the electrical system that excite the wire or by the excess of frequency limit measurement due for instance to important creep strains [1,2]. Most of these sensors have been embedded in the concrete during construction and are thus irreplaceable. To overcome this loss of information, one of the solutions is to replace these defective embedded sensors by surface sensors.

Nevertheless, unlike central strain (far from outer surface), skin strain (near outer surfaces) is strongly affected by the environmental condition variations. Temperature and humidity cycles (daily and seasonal) generate thermo-hydric volume change. Other phenomena such as solar radiation, rain or wind, also disrupt these two important fields. Finally, characteristic times and so influence depths of these phenomena are very different. For these reasons, the analysis of this new data is more complex than embedded measures for which usual statistical analysis methods are employed.

The present contribution aims at comparing the time evolution of strain through the depth in thick structure. This can be considered as a first step toward the complete definition of a space and time transfer functions between both strain vs time signals.

For this purpose, a finite element model with a time dependent thermo-hydro-mechanical constitutive model of concrete submitted to variable thermo-hydric boundary conditions was realized.

To be applicable to major civil engineering thick structures, the numerical model must account for thermal and hydric variation effects on strains. Thermo-mechanical [6], hydro-mechanical [3] and thermo-hydric [5] weak coupling are retained. In contrast, the effects of mechanical strains on thermal and hydric properties [7] and the modification of heat and water diffusivity due to cracked skin are neglected. Finally, for ageing structures, hydration reaction is supposed finished. Constitutive models adopted are mostly empirical although based on physical approaches.
\end{abstract}


Thermal field is assumed to be governed by a conventional linear heat equation with convective boundary conditions. Specific heat capacity, thermal conductivity and heat transfer coefficient (taking into account convection and radiation) are taken constant during all the calculation.

Drying process is modeled by a nonlinear diffusion equation involving a diffusion coefficient (nonlinear function of water content). The expression used, proposed by Granger [4], is composed of the drying coefficient proposed by Mensi and the temperature dependence given by Bazant. The isotherm between relative humidity (boundary condition measured) and water content of concrete is supposed linear (the hysteresis existing between sorption and desorption cycles is neglected) in the humidity range between $40 \%$ and $100 \%$. The convective boundary condition used involves a water exchange coefficient which is assumed constant.

This study focuses on operating structures during service life. Consequently damage rate is assumed to be low and a simple elastic model is used. Under the assumption of small strains, the total strain tensor is assumed to be the sum of five tensorial components: elastic strain, thermal strain (assumed to be proportional to the temperature change), drying shrinkage strains (assumed to be proportional with water variation content), basic creep strains (based on simple rheological models) and drying creep strain (assumed to be linear with strain and internal relative humidity variations [8]).

Complete simulations are carried out using Code_Aster by chaining these three calculations: thermal field, hydric field and mechanical strains.

After a thorough calibration of material parameters for each modeled phenomena on laboratory tests, an application to a representative volume of a confinement vessel of a nuclear power plant was achieved. For this simulation, an inner containment wall of a double containment vessel is studied which allows the suppression of the direct effects of rain, wind and solar radiation; only thermal and humidity variations, load and prestressing were selected as thermo-hydro-mechanical boundary conditions.

The mesh of a current portion of containment in three dimensions, taking into account reinforcements was used.

The calculation simulates 30 years of service life of the structure (preloading, operating, pressuring tests...). The thermo-hygrometric boundary conditions were created by duplicating periodic temperature and humidity measurements from the studied structure. In-situ mechanical boundary conditions are represented by the following hypothesis: on the bottom and lateral faces, normal displacements are prohibited and the upper side is forced to remain parallel to the bottom side.

The orthoradial strains numerically obtained on the outer surface and near the center of the structure are presented in Figure 1. For confidentiality reasons, the strains are normalized by the absolute value of the center strain at 30 years.

The results of this study show that, unlike thermal variations which affect the entire thickness of the structure, creep kinetics are not the same between the center and the surface of the structure. Creep is smaller near the exchange surfaces, where concrete has a lower water content. Under the hypothesis used in the numerical part, this contribution shows that the strain evolution between the core and the surface of the structure are not exactly the same. After 30 years, this difference is about $5 \%$.

This confirms that the identification of a transfer function is necessary between strain measurement at various depth. Given the above results, a simple reduction of the strain depending on the distance to the outer sides could be accurate enough.

Benefiting from a representative structure, built in the same concrete used for the calibration procedure and instrumented with surface strain sensors for several years, this present work will continue with a comparison between simulated strain and measured strain. 


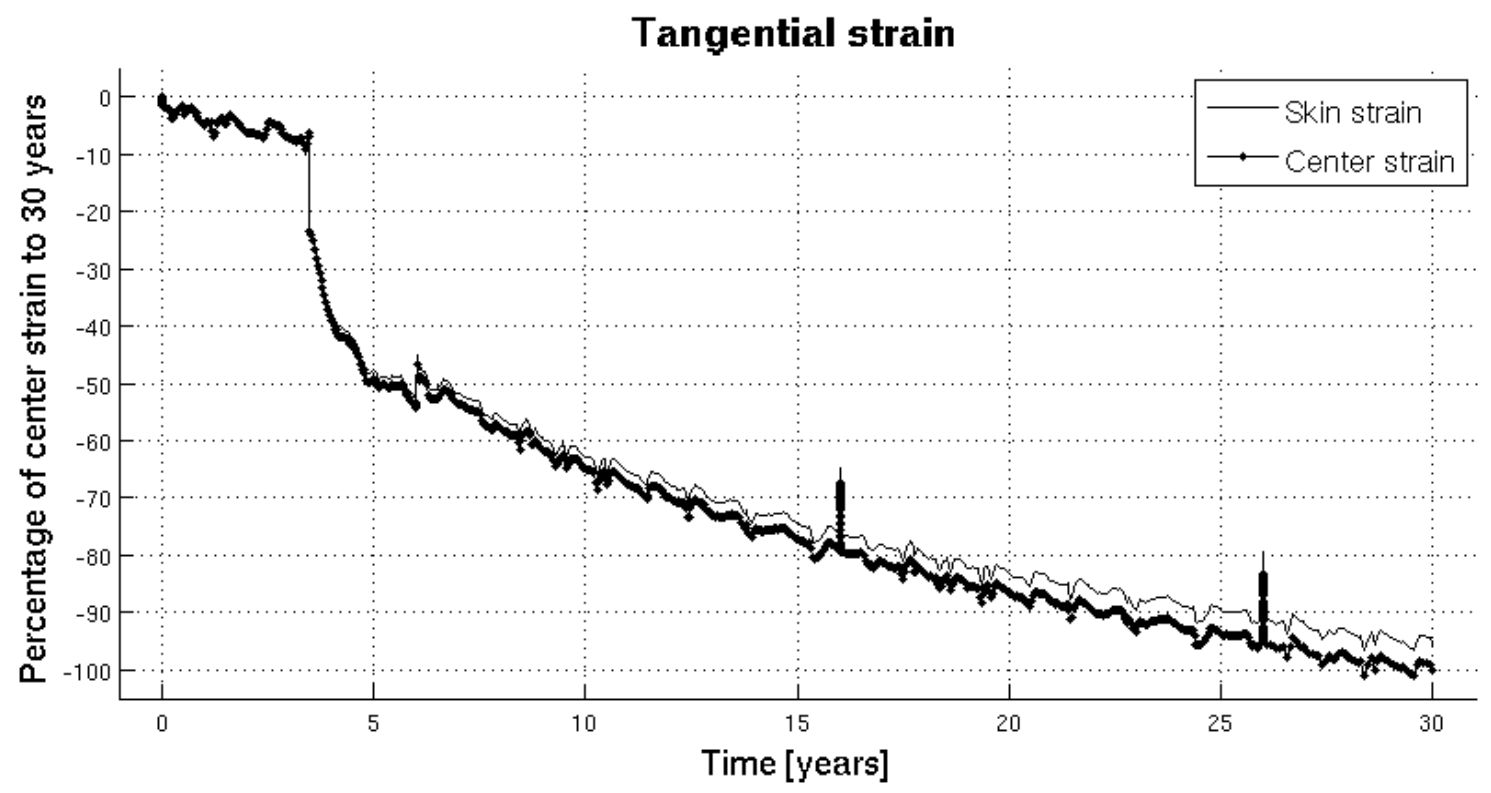

Figure 1. Tangential strain on outer surface and close to the center of structure.

\section{References}

[1] A. Simon, A. Courtois, Structural monitoring of prestressed concrete containments of nuclear power plants for ageing management, SmiRT 21, 2011.

[2] A. Simon, E. Oukhemanou, A. Courtois, Structural monitoring of prestressed concrete containments of nuclear power plants for ageing management, TINCE 2013, 2013.

[3] F. Wittmann, Interaction of hardened cement paste and water, Journal of the American ceramic society, 1973.

[4] L. Granger, Comportement différé du béton dans les enceintes de centrales nucléaires : analyse et modélisation, 1995.

[5] S. Caré, Effect of temperature on porosity and on chloride diffusion in cement pastes, Construction and Building Materials, 2008.

[6] S. Seki, M. Kawasumi, Creep of concrete at elevated temperatures, Concrete of nuclear reactors, 1972.

[7] T. Lassabatere, J.M. Torrenti, L. Granger, Sur le couplage entre séchage du béton et contrainte appliquée, 1997.

[8] Z.P. Bazant, J.C. Chern, Concrete creep at variable humidity : constitutive law and mechanism, Matériaux et Constructions, 1985. 